\title{
QUEDA DA PRODUTIVIDADE DE PESCADO NO RIO TOCANTINS: A PERCEPÇÃO DOS PESCADORES DE MARABÁ - PARÁ
}

\author{
Sandro Ferreira Nascimento ${ }^{1}$; Andréa Hentz de Mello²; Gustavo Ferreira de Oliveira ${ }^{3}$; \\ Verônica Danielle Nascimento Pereira ${ }^{4}$; Aila da Silva Mendes ${ }^{4}$. \\ ${ }^{1}$ Engenheiro agrônomo, Bolsista Pibex-Água 2010-2011, sandro-fn@ hotmail.com \\ ${ }^{2}$ Professora Adjunta II, Universidade Federal do Pará, Campus Universitário de Marabá, Faculdade de Ciências \\ Agrárias, Universidade Federal do Pará, andreahentz@ufpa.br \\ ${ }^{3}$ Discente do Curso de Agronomia da UFPA da Faculdade de Ciência Agrárias de Marabá, Universidade Federal do \\ Pará, Bolsista Pibex-Água 2010-2011, gustavo_mania21@ @otmail.com \\ ${ }^{4}$ Discente do Curso de Agronomia da UFPA da Faculdade de Ciências Agrárias de Marabá, Universidade Federal do \\ Pará, Bolsista voluntário
}

\begin{abstract}
RESUMO: A ação combinada entre a falta de políticas públicas adequadas para a Amazônia e as alterações do regime hidrológico do rio Tocantins tem provocado o aumento da prática da pesca e afetado a disponibilidade do pescado no Rio Tocantins. A complexidade da organização das relações sociais organizadas às margens do rio Tocantins, leva a discutir as formas de apropriação e manejo dos recursos hídricos, enfoque de âmbito ecológico, refletir também a sobrevivência social e econômica de núcleos e localidades. É neste contexto que este trabalho objetivou mostrar as percepções dos pescadores moradores às margens do rio sobre a produtividade do pescado no rio Tocantins em Marabá. Para tanto, foram aplicados questionários semi-estruturados nas principais comunidades de pescadores moradores da margem esquerda do rio Tocantins na área urbana de Marabá (bairros Francisco Coelho, Santa Rita e Santa Rosa) de forma aleatória. Os pescadores consideraram que a construção da hidrelétrica de Tucuruí foi a principal causa da queda da produtividade de pescado na região, e, além disso, faltam ações do Estado de maneira a qualificar esta atividade de acordo com os interesses locais.
\end{abstract}

PALAVRAS CHAVE: impactos ambientais, organização social, recursos hídricos.

\section{FALL OF PRODUCTIVITY OF FISH IN RIO TOCANTINS: PERCEPTIONS OF FISHERMEN MARABÁ - PARA}

\begin{abstract}
The combination between the lack of adequate public policies for the Amazon and the changes in the hydrological regime of the Tocantins river is causing the increased practice of fishing and affecting the availability of fish in the river Tocantins. The complexity of the organization of social relations organized on the river Tocantins, leads to discuss the forms of ownership and management of water resources, the ecological approach, also reflecting the social and economic survival of cores and locations. It is in this context that this paper we show the perceptions of fishermen living along the river on the productivity of fish on the Tocantins river in Marabá. Thus, we applied semi-structured questionnaires in the main fishing communities living on the left bank of the Tocantins river in the urban area of Marabá (neighborhoods Francisco Coelho, Santa Rita and Santa Rosa) at random. The fishermen felt that the construction of hydroelectric Tucuruí was the main cause of reduced productivity of fish in the region, and, furthermore, lack of state action in order to qualify this activity according to local interests.
\end{abstract}

KEY-WORDS: ambient impacts, social organization, water resources. 
Nos últimos anos no Rio Tocantins, em Marabá, nota-se a diminuição do total de peixes, provavelmente como resultado de uma ação de falta de políticas públicas adequadas para a Amazônia e as alterações do regime hidrológico provocado pela operação da barragem hidrelétrica de Tucuruí no rio Tocantins, combinadas com o aumento sistemático ao longo dos anos da prática de pesca na região (BORGO, 2007).

Segundo Araújo (2005) o período de safra em Marabá ocorre de junho a setembro com 71,59\% da produção anual, e dados da Colônia de Pescadores Z-30 de Marabá, revelaram que das 25 espécies desembarcadas, apenas 7 espécies apresentam expressão comercial. O mapará (Hypophthalmus marginatus), pescada (Plagioscion sp.), piau (Leporinus sp.), voador (spp.), curimatá (Prochilodus lineatus), branquinha (Curimata inornata) e tucunaré (Cichla sp.), representam 93,76\% de toda a produção. As espécies mapará e pescada juntas, representam $64 \%$ do total desembarcado. As outras espécies restantes respondem por apenas $6,24 \%$.

Neste sentido Issac (2006) relatou que o primeiro sinal do efeito da pesca é a diminuição dos exemplares maiores da população e a captura de indivíduos cada vez mais jovens. A exploração da pesca de crescimento acontece quando as mortes causadas pela captura excessiva superam a capacidade de crescimento dos indivíduos restantes da população, ou seja, os peixes são capturados antes mesmo de que possam crescer o suficiente, como para contribuir substancialmente com a biomassa do estoque.

Ao longo da formação histórica das sociedades e do surgimento das primeiras civilizações, cidades e rios constituíram-se em importantes elos de fusão. Essa conexão está presente na fase colonial e moderna de ocupação ao longo do rio Tocantins, onde se consolidam os núcleos urbanos em Marabá. Assim, a complexidade da organização das relações sociais organizadas às margens do rio Tocantins, leva a discutir as formas de apropriação e manejo dos recursos hídricos, enfoque de âmbito ecológico, refletir também a sobrevivência social e econômica de núcleos e localidades. Todavia, não se trata no mundo "ecologizado", de atentar somente para o papel estratégico que a Amazônia representa na atual crise da água do planeta e dos problemas advindos da super exploração dos recursos naturais, mas de investigar as interrelações do ambiente aquático com a sobrevivência da comunidade ribeirinha, bem como a saúde e sustentabilidade humana, visando à prevenção de doenças e preservação ambiental dos grupos que aqui criam seus meios de existência (BORGO, 2007).

É dentro dessa perspectiva que surge a necessidade de investigação sobre o tema através do qual procura-se entender a dinâmica vivida pelos pescadores e pelas comunidades ribeirinhas locais, bem como sobre a saúde humana, do ponto das atividades antropogênicas que podem ser 
prejudiciais à própria saúde do homem. Assim, foi conduzido trabalho com o objetivo de mostrar as percepções dos pescadores moradores às margens do rio Tocantins sobre a produtividade do pescado em Marabá-PA.

As informações sobre a percepção dos pescadores foram obtidas através da aplicação de questionários semi-estruturados nas principais comunidades de pescadores moradores da margem esquerda do rio Tocantins na área urbana de Marabá. Foram entrevistados pescadores moradores dos bairros Francisco Coelho, Santa Rosa e Santa Rita. Essa amostragem foi aleatória e composta por 58 famílias que possuem residências que se situam a até 300 metros de distância da margem do rio entre os meses de fevereiro e março de 2011.
Os dados foram sistematizados e analisados no software Microsoft Office Excel 2007, alem disso, as discussões foram subsidiadas juntamente com as observações de campo e outros relatos espontâneos dos moradores durante as entrevistas.

A maior parte dos entrevistados (43\%) reside às margens do rio Tocantins entre um e nove anos (Figura 1), resultado este que se diferenciou dos dados levantados por Borgo (2007), o qual a maior parte dos entrevistados ficou no intervalo de 10 a 19 anos de moradia, este fato pode ter ocorrido pelo fluxo migratório da população ocasionado pela cheia do rio.

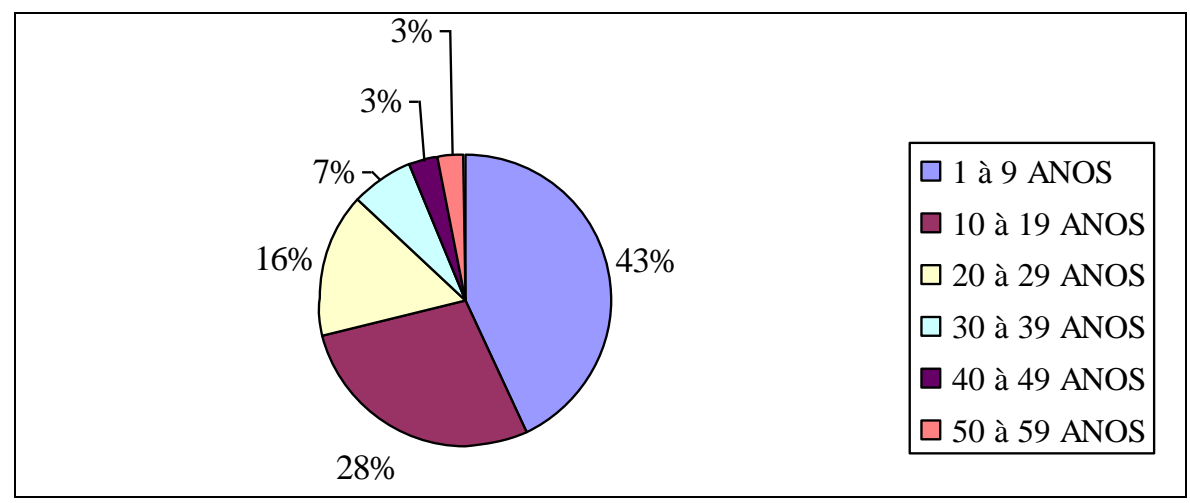

Figura 1. Tempo de residência dos moradores das margens do rio Tocantins em Marabá.

De acordo com os pescadores moradores da margem esquerda do rio Tocantins as principais causas da queda da produtividade de pescado na região são: arrastão, aumentos do número de pescadores, falta de fiscalização, pesca predatória, poluição do rio 
e a barragem hidrelétrica de Tucuruí, sendo esta apontada por $47 \%$ dos entrevistados (Figura 2). No estudo conduzido por Borgo
(2007), além desses fatores são evidenciados também o uso de redes de malha fina e pesca no período da piracema.

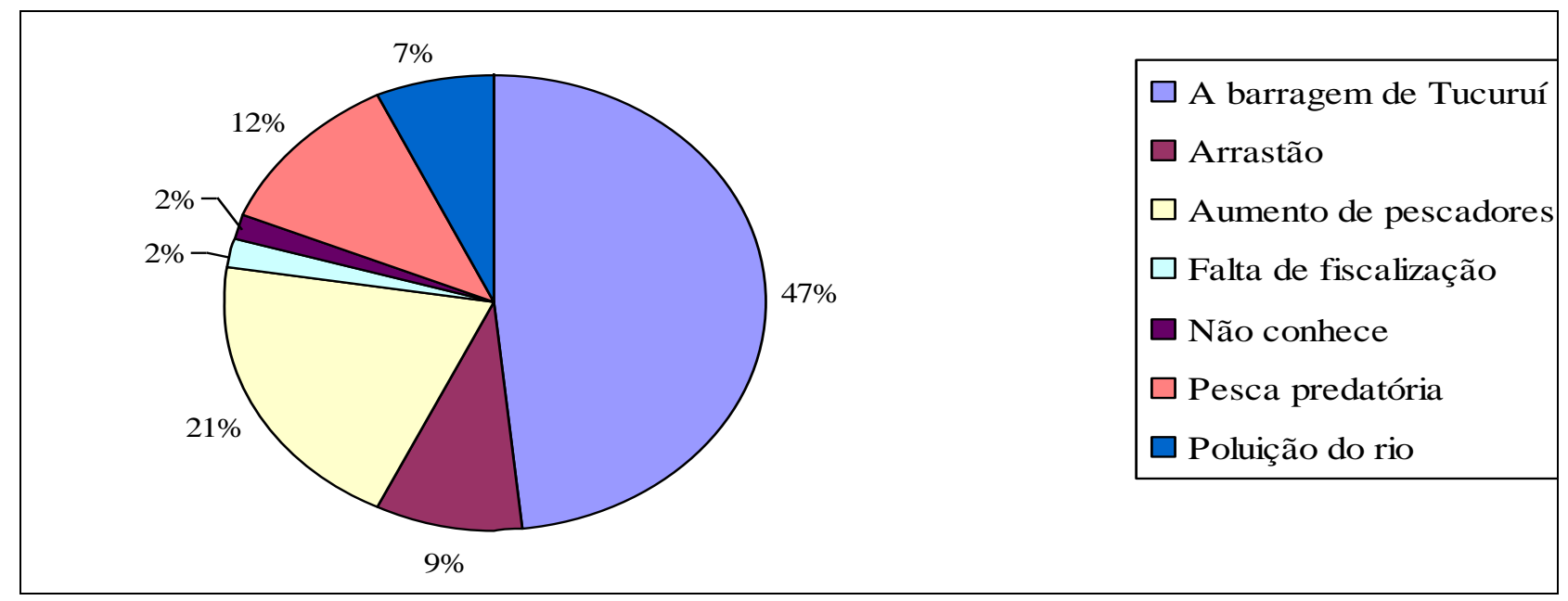

Figura 2. Motivos da queda da produtividade de pescado de acordo com os pescadores da margem esquerda do rio Tocantins em Marabá - PA.

Quando perguntados sobre o que fazer para melhorar a atividade pesqueira nessa região do rio Tocantins, os moradores pescadores, conforme apresentado na figura 4 , evidenciaram com mais ênfase o aumento da fiscalização (33\%) e a paralisação da pesca por um período de três anos $(15 \%)$, pois consideram que este é um período suficiente para o restabelecimento dos peixes nessa região. Esses resultados demonstram a falta de atuação do poder público para com esta classe social e também denota consciência ambiental por parte dos pescadores.

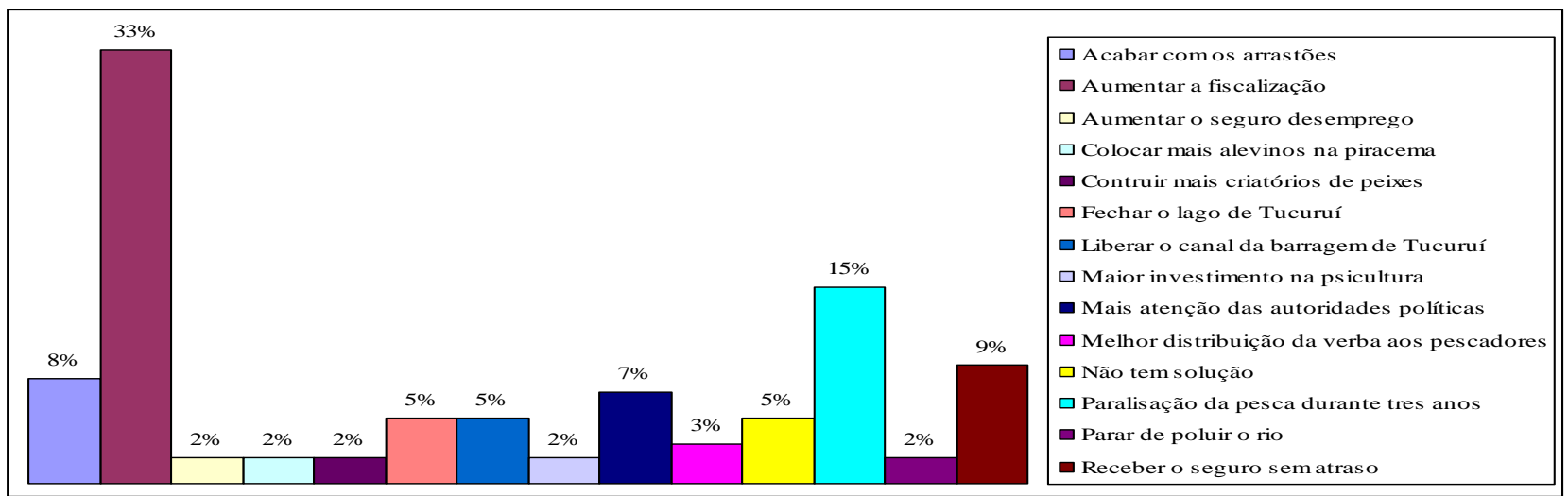

Figura 3. Soluções apresentadas pelos pescadores moradores para melhorar a atividade pesqueira na região de Marabá. 
Na percepção dos pescadores moradores da margem esquerda do rio Tocantins em Marabá, a principal causa da queda na produtividade de pescado na região foi a construção da hidrelétrica de Tucuruí.

A ausência de políticas públicas que qualifique a atividade pesqueira na região de Marabá depende ainda de ações básicas do Estado como a fiscalização. Destaca-se também a consciência ambiental desses pescadores de que seria necessário ficar um período de três anos de paralisação dessa atividade, no entanto, sem a atuação do Estado nesse processo, esta se torna uma ação inviável para estes pescadores.

\section{REFERÊNCIAS}

ARAÚJO, R. $\mathrm{S}$ de. $\mathrm{O}$ pescado como alimento em Marabá - PA. 2005, 128 f. Trabalho de Conclusão de Curso (Tecnologia Agroindustrial) - Universidade Estadual do Pará, Marabá 2005.

BORGO, J. D. H. Água e sociedade: diagnóstico do uso socioeconômico e ambiental do rio Tocantins em Marabá -

PA. 2007, 143 f. Trabalho de Conclusão de Curso (Bacharelado em Agronomia) Faculdade de Ciências Agrárias, Universidade Federal do Pará, Marabá, 2008.

ISSAC, V, J. Reflexões de uma política de pesca na Amazônia. Belém de Águas e Ilhas. Belém: CEJUP, 2006. 402 p. 